\title{
Research on the Development of Science and Technology in Guangdong by Using Grey Incidence Evaluation Method
}

\author{
-------Based on the Comparative Analysis of Science and Technology Data in Jiangsu \\ Province \\ Feng Wei ${ }^{a}$, and Qiong $W u^{b^{*}}$ \\ ${ }^{a}$ Postgraduate Office, Guangxi University of Science and Technology, GXUT, Liuzhou, China \\ ${ }^{\mathrm{b}}$ School of Management, Guangxi University of Science and Technology, GXUT, Liuzhou, China \\ *Corresponding author: Qiong Wu, wqssx@126.com
}

\begin{abstract}
The development of science and technology in Jiangsu province has made great progress. In contrast, the development in Guangdong is slightly inferior. This article puts Guangdong and Jiangsu as comparative objects. After selecting data from 2002 to 2013, this paper analysis the grey incidence between the input indexes and the output indexes in these two provinces by using Grey Incidence Evaluation, and eventually finds obstacles for the development of science and technology in Guangdong.
\end{abstract}

Keywords: input and output indexes, grey incidence evaluation, science and technology in Guangdong

\section{Introduction}

As the main body in the Pearl River Delta economic zone, Guangdong province implements the strategies of science and technology actively and gradually becomes a strong province of science and technology in our country. Although Guangdong province occupies a leading position in science and technology for a long time, especially in patent applications [1], the weak capacity for independent innovation and the lack of high-level talents in science and technology become obstacles to the further development for Guangdong province [2]. For now, most of the researches about science and technology in Guangdong focus on the character descriptions and the efficiency evaluation in technology input-output. Qiong Zeng, Zhaohui Xuan(2012)analyzed seven core indexes in science and technology of Guangdong province, and clearly pointed out that the combination between Guangdong economy and Guangdong technology needs to go further [3];Gangming Zou,Yafei Tang(2010)analyzed the changes of main indexes in Guangdong technology and pointed out that Guangdong needs to strengthen scientific and technological innovation ability. Besides, the proportion of government investment in science and technology has to be adjusted [4]; Murong Yang, Yafei Tang(2011) discussed the output indexes of the science and technology in Guangdong, Comprehensively evaluated the output capacity in Guangdong technology[5].Although these studies are intuitive ,they still lack the support of related theory and quantitative model. When it comes to the quantitative research, many scholars focus on evaluating the input-output efficiency. Most scholars use Data Envelopment Analysis research the input-output efficiency of science and technology in Guangdong quantitatively: Qiang Xu,Chunzeng Fan(2010) evaluated the input-output efficiency of five provinces(including Guangdong province) by using DEA, and concluded that the resources of science and technology should be utilized more effectively to improve the output [6]; Li Wang, Mintun Li(2010)measured the efficiency 
of science and technology input-output in Guangdong by using models in DEA and pointed out that the huge technological investment in Guangdong province is a drive force to the development of technology [7]. While such studies provided a macro judgment in the efficiency of technological input and output in Guangdong province, they still lack accurate identification of the most significant input index which affects one specific output index. This paper uses the Grey incidence evaluation method study the efficiency in science and technology input and output to accomplish some improvement in this research field. Besides, the quantitative studies in this research field lack comparison with other provinces. Thus the advanced experiences in other provinces can not be introduced to Guangdong. As a rising star in the development of science and technology, Jiangsu province can offer many experiences to Guangdong. This paper compares and analyzes some input indexes and output indexes in these two provinces to provide some advice in the development of science and technology for Guangdong.

\section{The Building of Measure Index System}

\subsection{Input and Output Indexes Selection}

The input indexes and output indexes in this paper are chosen on the basis of relative literature. Considering the authenticity of data and the difficulties in collection, local financial allocation for sci-tech in Guangdong province (code X1), the quantity of science and technology personnel in Guangdong province(code X2) and the number of research institutions in Guangdong(code X3) are chosen as the input indexes [8]. Same input indexes are chosen in Jiangsu province, and they are coded by X4,X5,X6 correspondingly.

Quantity of patent authorization (code Y1) and national technology reward (code Y2) in Guangdong are chosen as direct technology output indexes. Volume of business in technology market in Guangdong (code Y3) is chosen as an indirect technology output index. These indexes aim to judge the level of the development of science and technology in Guangdong. Same output indexes are chosen in Jiangsu province, and they are coded by Y4, Y5, and Y6 correspondingly.

\subsection{Data Selection}

Statistic data analyzed in this article needs to be approved by Statistical Bureau, so the data will be overt in two years later. The latest data we can get is the data of 2013.By searching overt data in Technology Bureau and Statistical Bureau of these two provinces, data of indexes from 2002 to 2013 are summarized in the Table 1.

\section{Grey Incidence Analysis}

\subsection{Introduction of Grey System Theory}

The Grey System Theory was founded in the 1980s.In 1981, the conception of "Grey System” was put forward for the first time by professor Julong Deng in one of his academic reports. The Grey System contains both known information and the unknown information. The Grey System Theory is applied to do some relevant research in this kind of system, which means studying the known information to describe and predict the unknown information until we understand the whole system eventually. 
Table 1 - Data of Science and Technology Input and Output Indexes in Two Provinces(2002-2013)

\begin{tabular}{|c|c|c|c|c|c|c|c|c|c|c|c|c|}
\hline \multirow[t]{2}{*}{ Year } & \multicolumn{2}{|c|}{$\begin{array}{l}\text { Quantity of } \\
\text { patent authorization } \\
\text { (item) }\end{array}$} & \multicolumn{2}{|c|}{$\begin{array}{l}\text { Volume of business in } \\
\text { technology market } \\
\text { (billion yuan) }\end{array}$} & \multirow{2}{*}{\multicolumn{2}{|c|}{$\begin{array}{l}\text { National } \\
\text { sci-tech } \\
\text { award } \\
\text { (item) } \\
\text { Guang Jiang }\end{array}$}} & \multicolumn{2}{|c|}{$\begin{array}{l}\text { Local financial } \\
\text { allocation for sci-tech } \\
\text { (billion yuan) }\end{array}$} & \multicolumn{2}{|c|}{$\begin{array}{l}\text { Quantity of sci-tech } \\
\text { personnel } \\
\text { (000 people) }\end{array}$} & \multicolumn{2}{|c|}{$\begin{array}{l}\text { Number of research } \\
\text { institutions } \\
\text { (item) }\end{array}$} \\
\hline & $\begin{array}{l}\text { Guang } \\
\text { dong }\end{array}$ & $\begin{array}{c}\text { Jiang } \\
\text { su }\end{array}$ & $\begin{array}{l}\text { Guang } \\
\text { dong }\end{array}$ & $\begin{array}{l}\text { Jiang } \\
\text { su }\end{array}$ & & & $\begin{array}{l}\text { Guang } \\
\text { dong }\end{array}$ & $\begin{array}{c}\text { Jiang } \\
\text { su } \\
\end{array}$ & $\begin{array}{l}\text { Guang } \\
\text { su }\end{array}$ & ng dong & $\begin{array}{l}\text { Guang } \\
\text { dong }\end{array}$ & $\begin{array}{l}\text { Jiang } \\
\text { su }\end{array}$ \\
\hline 2002 & 22761 & 7595 & 68.45 & 59.45 & 13 & 13 & 57.70 & 9.86 & 8.69 & 30.73 & 2907 & 2907 \\
\hline 2003 & 29235 & 9840 & 80.57 & 76.52 & 14 & 19 & 56.58 & 17.79 & 9.38 & 33.18 & 2726 & 2726 \\
\hline 2004 & 31446 & 11330 & 57.27 & 89.79 & 21 & 24 & 65.37 & 26.79 & 9.52 & 33.55 & 2994 & 3765 \\
\hline 2005 & 36894 & 13580 & 112.47 & 100.83 & 15 & 31 & 83.77 & 35.68 & 12.21 & 38.17 & 3181 & 3751 \\
\hline 2006 & 43516 & 19352 & 107.03 & 68.83 & 19 & 35 & 104.10 & 54.41 & 14.71 & 38.11 & 3414 & 3620 \\
\hline 2007 & 56451 & 31770 & 133.86 & 78.42 & 29 & 52 & 119.26 & 68.73 & 20.00 & 43.79 & 3678 & 3898 \\
\hline 2008 & 62031 & 44438 & 184.78 & 94.02 & 30 & 47 & 132.52 & 91.52 & 24.00 & 53.59 & 4200 & 4761 \\
\hline 2009 & 83621 & 87286 & 247.93 & 108.22 & 26 & 51 & 168.50 & 117.02 & 28.37 & 67.17 & 4280 & 7521 \\
\hline 2010 & 119343 & 138382 & 242.50 & 249.34 & 36 & 47 & 214.44 & 150.35 & 34.47 & 73.69 & 4452 & 6798 \\
\hline 2011 & 128413 & 199814 & 286.62 & 333.43 & 34 & 56 & 203.92 & 213.4 & 41.08 & 81.62 & 4535 & 9061 \\
\hline 2012 & 153598 & 269944 & 369.75 & 400.91 & 26 & 53 & 246.71 & 257.24 & 49.23 & 98.23 & 4756 & 17776 \\
\hline 2013 & 170430 & 239645 & 535.86 & 527.50 & 28 & 60 & 344.94 & 302.59 & 50.17 & 108.08 & 5030 & 19335 \\
\hline
\end{tabular}

As a significant research method in Grey System Theory, grey incidence analysis plays an important role in quantitative research. In essence, the grey incidence analysis is comparing the similarity of different time sequences or space sequences. The sequences which have greater similarity are of incidence at a higher degree. Calculating the degree of grey incidence is the key to grey incidence analysis. Bigger degree of grey incidence between two factors shows the changing tracks of these two factors matched in a higher degree and vice versa.

\subsection{Construction of grey incidence analysis model}

First of all, put the sci-tech output indexes in each province as character sequences which coded Yi (i=1,2,3,4,5,6), Yi=[yi (1),yi (2),yi (3),... yi (n)].In these character sequences, "n” is characterized as the number of data in each character sequence. As data selected in this paper comes from 2002 to 2013, the valuation of “n” is 12 .

Secondly, solving the grey incidence coefficient of $\mathrm{Yi}$ and $\mathrm{Xj}$ (coded $^{\gamma_{i j}}{ }^{(k)}$ )by the following formula(1):

$$
\begin{aligned}
& \gamma_{i j}(k)=\frac{\min _{i} \min _{j}\left|y_{i}(k)-x_{j}(k)\right|+\xi \max _{i} \max _{j}\left|y_{i}(k)-x_{j}(k)\right|}{\left|y_{i}(k)-x_{j}(k)\right|+\xi \max _{i} \max _{j}\left|y_{i}(k)-x_{j}(k)\right|} \\
& (\mathrm{i}=1,2, \ldots, 6 ; j=1,2, \ldots, 6), \xi \in(0,1)
\end{aligned}
$$

In formula (1), ${ }^{\xi}$ is the distinguishing coefficient to reduce the data distortion caused by the maximum difference of absolute value. In empirical research, better calculated results appears when $\xi$ is valued by 0.5 .

Last but not least, define ${ }^{\gamma_{i j}}(\mathrm{i}=1,2, \ldots, 6 ; \mathrm{j}=1,2, \ldots, 6)$ as the degree of grey incidence between $\mathrm{Yi}$ and $\mathrm{Xj}$. Solving $\gamma_{i j}$ by using formula (2) and get the grey incidence matrix of the sci-tech input and output in these two provinces.

$$
\begin{gathered}
\gamma_{i j}=\frac{1}{n} \sum_{k=1}^{n} \gamma_{i j}(k) \\
(\mathrm{i}=1,2, \ldots, 6 ; \mathrm{j}=1,2 \ldots, 6)
\end{gathered}
$$




\subsection{Solving the degree of grey incidence and the grey incidence matrix}

As the dimensions of indexes in the measure system are different, the original data in Tab2.1 need to be non-dimensional. All the indexes in measure system are benefit-type data, and transforming this type of data into interval values by using formula (3) is common in empirical research.

$$
Y_{i}^{\prime}=\frac{Y_{i}(k)-\min Y_{i}(k)}{\max Y_{i}(k)-\min Y_{i}(k)} \quad X_{j}^{\prime}=\frac{X_{j}(k)-\min X_{j}(k)}{\max X_{j}(k)-\min X_{j}(k)}
$$

$(\mathrm{k}=1,2, \ldots, \mathrm{n})$

After making the data non-dimensional, solve the grey incidence coefficient of specific sequences in Guangdong by using formula (1) and solve ${ }^{\gamma_{i j}}(\mathrm{i}=1,2,3 ; \mathrm{j}=1,2,3)$ by using formula (2).

$$
\begin{array}{lll}
\gamma_{11}=\frac{1}{n} \sum_{k=1}^{n} \gamma_{11}(k)=0.769 & \gamma_{12}=\frac{1}{n} \sum_{k=1}^{n} \gamma_{12}(k)=0.642 & \gamma_{13}=\frac{1}{n} \sum_{k=1}^{n} \gamma_{13}(k)=0.639 \\
\gamma_{21}=\frac{1}{n} \sum_{k=1}^{n} \gamma_{21}(k)=0.744 & \gamma_{22}=\frac{1}{n} \sum_{k=1}^{n} \gamma_{22}(k)=0.684 & \gamma_{23}=\frac{1}{n} \sum_{k=1}^{n} \gamma_{23}(k)=0.530 \\
\gamma_{31}=\frac{1}{n} \sum_{k=1}^{n} \gamma_{31}(k)=0.586 \quad \gamma_{32}=\frac{1}{n} \sum_{k=1}^{n} \gamma_{32}(k)=0.584 & \gamma_{33}=\frac{1}{n} \sum_{k=1}^{n} \gamma_{33}(k)=0.562
\end{array}
$$

Getting the grey incidence matrix of the sci-tech input and output in Guangdong province:

$\Gamma_{1}=\left(\begin{array}{lll}\gamma_{11} & \gamma_{12} & \gamma_{13} \\ \gamma_{21} & \gamma_{22} & \gamma_{23} \\ \gamma_{31} & \gamma_{32} & \gamma_{33}\end{array}\right)=\left(\begin{array}{lll}0.769 & 0.642 & 0.639 \\ 0.744 & 0.684 & 0.530 \\ 0.586 & 0.584 & 0.562\end{array}\right)$

Using the same method to form the grey incidence matrix of the sci-tech input and output in Jiangsu province:

$\Gamma_{2}=\left(\begin{array}{lll}\gamma_{44} & \gamma_{45} & \gamma_{46} \\ \gamma_{54} & \gamma_{55} & \gamma_{56} \\ \gamma_{64} & \gamma_{65} & \gamma_{66}\end{array}\right)=\left(\begin{array}{lll}0.579 & 0.573 & 0.799 \\ 0.689 & 0.726 & 0.671 \\ 0.643 & 0.653 & 0.609\end{array}\right)$

\subsection{The grey incidence analysis of sci-tech input and output indexes}

In grey incidence matrix coded ${ }^{\Gamma_{1}}$, sizing down the vertical causal and then getting an order which is $\gamma_{11}>\gamma_{12}>\gamma_{i 3}$. The order shows that the sci-tech output indexes are incident with local financial allocation for sci-tech in Guangdong province (code X1) in the highest degree. The significant drive force in the development of science and technology in Guangdong is the local financial allocation for sci-tech, which means the impetus from science and technology staff and research institutions are insufficient. Sizing down the row vectors and then getting another order which is ${ }^{\gamma_{1 j}}>\gamma_{2 j}>\gamma_{3 j}$. This order shows that the sci-tech input indexes are incident with the quantity of patent authorization (code Y1) in the highest degree. Incidence between the sci-tech input indexes and national technology reward (code Y2) in Guangdong is in a lowest degree. The difference of vertical causal in grey incidence matrix coded $\Gamma_{2}$ is not significant, which means that the sci-tech output items are pushed by the sci-tech input items equably in Jiangsu province.

Sizing down the row vectors in general and then getting an order which is ${ }^{\gamma_{5 j}}>\gamma_{6 j}>\gamma_{4 j}$. As is shown in this order, the sci-tech input indexes are of incidence with volume of business in technology market in Jiangsu (code Y6) in the highest degree. Incidence between the sci-tech input indexes and the quantity of patent authorization in Jiangsu (code Y4) is in a lowest degree. The sci-tech inputs make great contributions to the marketization of technological achievements and the increasing of national technology reward in Jiangsu province. 
Technological achievements are in a high level.

4 Obstacles to the Development of Science and Technology in Guangdong 4.1 Simplex propulsion to the science and technology developing

After analyzing the vertical causal in grey incidence matrices, the main propulsion to the development of science and technology in Guangdong province can be described as local financial allocation for sci-tech. And meanwhile, the impetus from science and technology staff and research institutions are insufficient. Abundant local financial allocation for sci-tech may insure the sci-tech outputs stay on a high level, but when there is a shortage of the local financial allocation for sci-tech,sci-tech outputs will decrease dramatically. Depending on the simplex propulsions to achieve the development of science and technology provides no help for the independent innovation of science and technology staff and the research institutions. Thus Guangdong province still has a long way to go in developing independent innovation.

\subsection{Lacking of high-level scientific and technological achievements}

Though Guangdong province has preponderant in patent application and authorization, the lacking of high level patents and the weak technology innovation ability still exist problem. Improving the quality of patents and the capability of independent innovation is of desideration for Guangdong province. The quantity of national sci-tech award in Guangdong province is less than it in Jiangsu province from 2010 to 2013, which means that developing the technology innovation ability is significant to Guangdong province. Only in a harmonious scientific and technological innovation environment, can the interactions of knowledge, information and technology be promoted to get high-level scientific and technological achievements.

\subsection{Lack marketization of scientific research achievements}

Technology market transaction contract amount is the main reflection of the technical transformation capacity. Compared with Jiangsu province, the incidence between the volume of business in technology market and the three sci-tech inputs is less, which means the marketization of scientific research achievements is lack in Guangdong province. Universities and research institutions in Guangdong target their researches to theoretical aspects and the improvement in academia in a long time. As a result, the research achievements in Guangdong province cannot satisfy the actual needs of society and the markets. An effective cooperation model of communication between businesses and universities in Guangdong is not established yet, so the lack of specific technique in the marketization of research achievements is serious.

\section{Suggestions on the Development of Science and Technology in Guangdong Province 5.1 Stimulations to sci-tech personnel and research institutions}

Only if the sci-tech personnel get the motivity of study and research, can the communication of research technology and sci-tech information be promoted. For now, most talents employment in enterprises, universities and scientific research institutions depend on the recommendation from relatives or friends in Guangdong, which means those talents who have no contacts get no access to the research fields. Effective marketization in science and 
technology human resources market and material or spiritual rewards for excellent scientific research talents can keep talents full of energy in study and research.

It is of significance to attach importance to the introduction and constructions of cultivate high-tech industrial park, key laboratory, engineering center and other major scientific research innovation platform. And meanwhile, Guangdong province should realize the importance of training for scientific research institution personnel and talent echelon construction. Giving rich and generous material reward to institutions which undertake a major research project is necessary.

\subsection{Making full use of advantages to produce high-level accomplishments}

Guangdong province that located in China's pearl river delta economic zone abuts to Hong Kong and Macao, which means it has a unique geographical advantage. The scientific and technical communication with Hong Kong, Macao and Taiwan areas can not only help Guangdong to understand the new trends of science and technology but also provide good experiences of developing independent innovation for Guangdong. Guangdong province should gradually establish the information sharing platform between itself and research institutions in Hong Kong, so that the sci-tech information can be updated and exchanged timely and effectively.

At the same time, Guangdong province should also alert the weak independent innovation caused by the over dependence on technology and resources in Hong Kong and Macao areas.

\subsection{Effective combination involving production, teaching \&research to improve the research achievements market conversion}

Reinforcing the integration of universities, research institutions and social enterprise can fundamentally solve the problem of low research achievements market conversion rate. Establishing the information communicating and sharing platform between companies, universities and enterprises to encourage talents in universities and research institutions to go into enterprises and the workshops, to understand the urgent technical problems that enterprises want to solve. At the same time, insuring wages and job security for talents temporary in enterprises or workshop who come from universities or research institution.

\section{Acknowledgement}

National social science fund, "Studies of governance framework on the sustainability of traditional manufacturing supply chain in the western region based on the ecological innovation view."(15B5Y077); Science and technology project in Guangxi Zhuang autonomous region, "The empirical analysis on benefits of scientific and technological personnel policy in Guangxi and comparative study with other provinces" (Guangxi association [2014] B - 02); "Research on the transformation of automobile industry driven by innovation profoundly in Xijiang economic belt.”(Soft science of Liuzhou city association for science and technology20140104 ); "Research on the ascension path of urban cultural competitiveness based on the construction of social science research base in universities.”; Research on graduate education in teaching research university serving local economic.(JGY2014119). 


\section{References}

1. M.R. Yang, Y.F. Tang, and X.P. Chen, Analysis on output capacity of science and technology in Guangdong province--compared with the output capacity of science and technology in Yangtze river delta, Science and Technology Management Research, 2011, vol. 5(6), pp. 75-79.

2. J.W. Duan, Research on the evaluation of technology innovation policy implementation in Guangdong province, Guangzhou:Jinan University, 2007.

3. Q. Zeng, and Z.H. Xuan, Research on the characteristics of science and technology development in different areas by analyzing main indexes in our country, Science \& Technology Progress and Policy, 2012, vol. 29(6), pp. 26-30.

4. G.M. Zou, and Y.F. Tang, Guangdong science and technology competitiveness research based on the analysis of the technology index, Science \& Technology Progress and Policy, 2010, vol. 27(2), pp. 37-40.

5. S.J. Xing, and J.Q. Tang, Study of Guangdong science and technology progress level based on the patent data, Science and Technology Management Research, 2014, vol. 46(24), pp. 136-143.

6. Q. $X u$, and C.Z. Fan, Science and technology input and output efficiency measure and evaluation in areas, Science and Technology Management Research, 2010, vol. 11(7), pp. 38-40.

7. W.M. Yang, and S.W. Song, The analysis of 20 city science and technology input and output efficiency in China, Science and Technology Management Research, 2013, vol. 35(7), pp. 52-55.

8. L. Wang, M.T. Li, and Q. Liu, Research on input and output of science and technology of Guangdong province based on DEA, Science and Technology Management Research, 2010, vol. 15(22), pp. 75-77. 